\title{
Predictors for Emergency Cesarean Delivery in Women with Placenta Previa
}

\author{
Laura Ruiter, MD ${ }^{1}$ Sanne J. Eschbach, $\mathrm{MD}^{2}$ Mara Burgers ${ }^{1}$ Katrien Oude Rengerink, $\mathrm{PhD}^{3}$ \\ Mariëlle G. van Pampus, MD, PhD Birgit Y. van der Goes, MSc ${ }^{5}$ Ben W. J. Mol, MD, PhD ${ }^{6,7}$ \\ Irene M. de Graaf, MD, $\mathrm{PhD}^{1}$ Eva Pajkrt, MD, $\mathrm{PhD}^{1}$
}

${ }^{1}$ Department of Obstetrics and Gynecology, Academic Medical Centre, Amsterdam, The Netherlands

2 Department of Obstetrics and Gynecology, Leiden University Medical Centre, Leiden, The Netherlands

3 Department of Obstetrics and Gynecology, University Medical Centre, Utrecht, The Netherlands

${ }^{4}$ Department of Obstetrics and Gynecology, Onze Lieve Vrouwe Gasthuis, Amsterdam, The Netherlands

${ }^{5}$ Department of Obstetrics and Gynecology, Spaarne Hospital, Hoofddorp, The Netherlands

${ }^{6}$ The Robinson Research Institute, School of Medicine, University of

Adelaide, South Australia, Australia

${ }^{7}$ The South Australian Health and Medical Research Institute,

Adelaide, South Australia, Australia

\author{
Address for correspondence Laura Ruiter, MD, Department of \\ Obstetrics and Gynecology, Academic Medical Centre, H4-240, Post \\ Box 226000, 1100DD Amsterdam, The Netherlands \\ (e-mail: I.ruiter@amc.nl).
}

Am J Perinatol 2016;33:1407-1414.

\begin{abstract}
Keywords

- placenta previa

- prediction

- cesarean section

- emergency delivery

Objective The objective of this study was to identify the predictors of emergency delivery in women with placenta previa.

Methods This is a retrospective study of pregnancies complicated by placenta previa, scheduled for a cesarean delivery between 2001 and 2011. Using univariable and multivariable regression predictors for emergency delivery in these women were determined. Predictive performance was assessed using receiver operating characteristic analysis and calibration plot. Internal validation was performed by bootstrap analysis.

Results Of 214 women with singleton pregnancies, 93 (43\%) had an emergency cesarean delivery, and 43 (20\%) were preterm. Independent predictors for emergency delivery were history of cesarean section (odds ratio [OR], 4.7; 95\% confidence interval $[\mathrm{Cl}], 1.2-12)$, antepartum bleeding with one (OR, 7.5; 95\% Cl, 2.5-23), two (OR, 14; 95\% $\mathrm{Cl}, 4.3-47)$, and three or more episodes (OR, $27 ; 95 \% \mathrm{Cl}, 8.3-90)$ as well as need for blood transfusion (OR, $6.4 ; 95 \% \mathrm{Cl}, 1.7-23)$. For emergency preterm delivery, covariates were comparable. The area under the curve was 0.832 on the original data and 0.821 on the bootstrap samples.

Conclusion Predictors for emergency delivery in women with placenta previa can be used for individualized antenatal care concerning timing of delivery and corticosteroid cover. Potentially, careful selection in women with placenta previa can result in more conservative treatment in an outpatient setting and reduction of iatrogenic preterm delivery.
\end{abstract}

received

February 2, 2016

accepted after revision

April 7, 2016

published online

May 16, 2016
Copyright $\odot 2016$ by Thieme Medical Publishers, Inc., 333 Seventh Avenue, New York, NY 10001, USA. Tel: +1(212) 584-4662.
DOI http://dx.doi.org/ 10.1055/s-0036-1584148. ISSN 0735-1631. 
When scheduling the delivery in women with placenta previa, maternal and neonatal risks need to be balanced. To allow optimal fetal maturation, cesarean delivery is generally recommended and scheduled after 37 to 38 weeks' gestation by international guidelines. ${ }^{1}$ However, up to $40 \%$ of women with placenta previa deliver before the scheduled date of cesarean delivery in an emergency or preterm setting ${ }^{2,3}$ and this is associated with peripartum hemorrhage, blood transfusion, and hysterectomy, ${ }^{4-7}$ as well as neonatal anemia, prematurity, and mortality. $2,8,9$

It is important to distinguish between women at high and low risk for emergency delivery. Women at high risk could receive corticosteroids and might have their cesarean delivery scheduled earlier, whereas women at low risk could be monitored without further intervention until 38 weeks.

Currently, there are no data that predict the risk of emergency delivery in women with placenta previa. In this study, we aim to identify factors that predict the risk of emergency delivery to select cases in which additional prenatal care and adapted timing of delivery can be considered and in which patients a more conservative treatment is justified.

\section{Methods}

\section{Setting and Population}

We identified women with a singleton pregnancy beyond 24 weeks scheduled for cesarean delivery because of placenta previa between January 2001 and December 2011 by reviewing all medical charts in one academic hospital and two teaching hospitals in the Netherlands. Pregnancies complicated by preeclampsia or hemolysis, elevated liver enzymes and low platelets (HELLP) syndrome were excluded, since emergency delivery might be indicated for other reasons than the location of the placenta.

Gestational age was based on last menstrual period and ultrasound measurements in the first trimester.

Classification of placenta previa is traditionally based on the relationship of the placenta to the internal cervical os and is reported as complete or partial. The term marginal placenta previa is used for those cases with placental tissue within $20 \mathrm{~mm}$ from the internal os. The diagnosis placenta previa is generally made during the transabdominal second trimester fetal anomalies scan performed by certified sonographers. If placenta previa is seen, placental localization will be evaluated by transvaginal ultrasound in the third trimester. In our study, the most recent ultrasound was used.

\section{Clinical Management of Placenta Previa}

Patients were admitted if vaginal bleeding was a reason for admission. If placenta previa was still present in the early third trimester, a cesarean delivery was scheduled from 37 weeks' gestation according to national guidelines. ${ }^{10}$

An emergency delivery was performed in cases of vaginal bleeding (premature) onset of labor or suspected fetal distress. Women with placenta previa presenting with symptoms of labor before 34 weeks were treated with corticosteroid cover for lung maturation and tocolytics if indicated. Emergency vaginal delivery was only accepted in patients already in advanced stage of labor at first evaluation.

\section{Outcome and Candidate Predictors}

The outcome was emergency delivery, that is, any delivery in emergent or semiemergent setting before the scheduled date of cesarean delivery documented in the medical chart. Emergency delivery was stratified in three groups: major or recurrent hemorrhage without signs of labor (hemorrhage), premature onset of labor described as contractions and/or ruptured membranes with or without hemorrhage (labor), and suspected fetal distress defined as nonreassuring fetal patterns on cardiotocography.

Candidate predictors were identified from literature and based on clinical reasoning. We extracted maternal characteristics including age, ethnicity, smoking, and body mass index and pregnancy characteristics including obstetric history, type of placenta previa (complete, partial, marginal based on ultrasound examination), and total amount of blood loss from the medical charts. Severity of antepartum bleeding was defined by the number of bleeding episodes, duration of hospital admission (more or less than 1 week), use of medication, and need for blood transfusion to compensate antepartum bleeding. The criteria for blood transfusion were hemodynamic instability and the pursuit of hemoglobin level $>6.0 \mathrm{mmol} / \mathrm{L}$. An episode of vaginal bleeding was defined as an admission or a presentation at the emergency room.

\section{Analysis}

A univariable preselection process was used to select variables with a $p$-value $\leq 0.20$. A multivariable model was constructed to identify independent predictors for emergency delivery in placenta previa using backward stepwise elimination. Variables with a $p$-value $<0.05$ remained in the final model. When more than one variable for severity of bleeding was significant, the variable with the most predictive value was used in the final model. Associations were expressed as odds ratios (ORs) with $95 \%$ confidence intervals (CIs). To test for differences between variables, chi-square and $t$-test were used where appropriate.

To evaluate the performance of the model, a calibration plot was constructed using five nearly equal sized groups based on predicted chance of emergency delivery. The area under the receiver operating characteristic (ROC) curve was studied, an area under the curve (AUC) of 1 means the model predicts perfectly in all cases, whereas an AUC of 0.5 means the model does not predict emergency delivery at all. Interval validation of the model was performed by bootstrapping to correct for optimistic prediction. We generated 1,000 bootstrap samples with replacement and evaluated the difference in AUC on the bootstrap sample and the original sample. ${ }^{11}$

Kaplan-Meier curves were constructed for women delivering before and on the scheduled date as well as for the three indications for emergency delivery. In addition, we compared the predictive factors between women who delivered early preterm before 34 weeks and women who delivered late preterm between 34 and 37 weeks. 


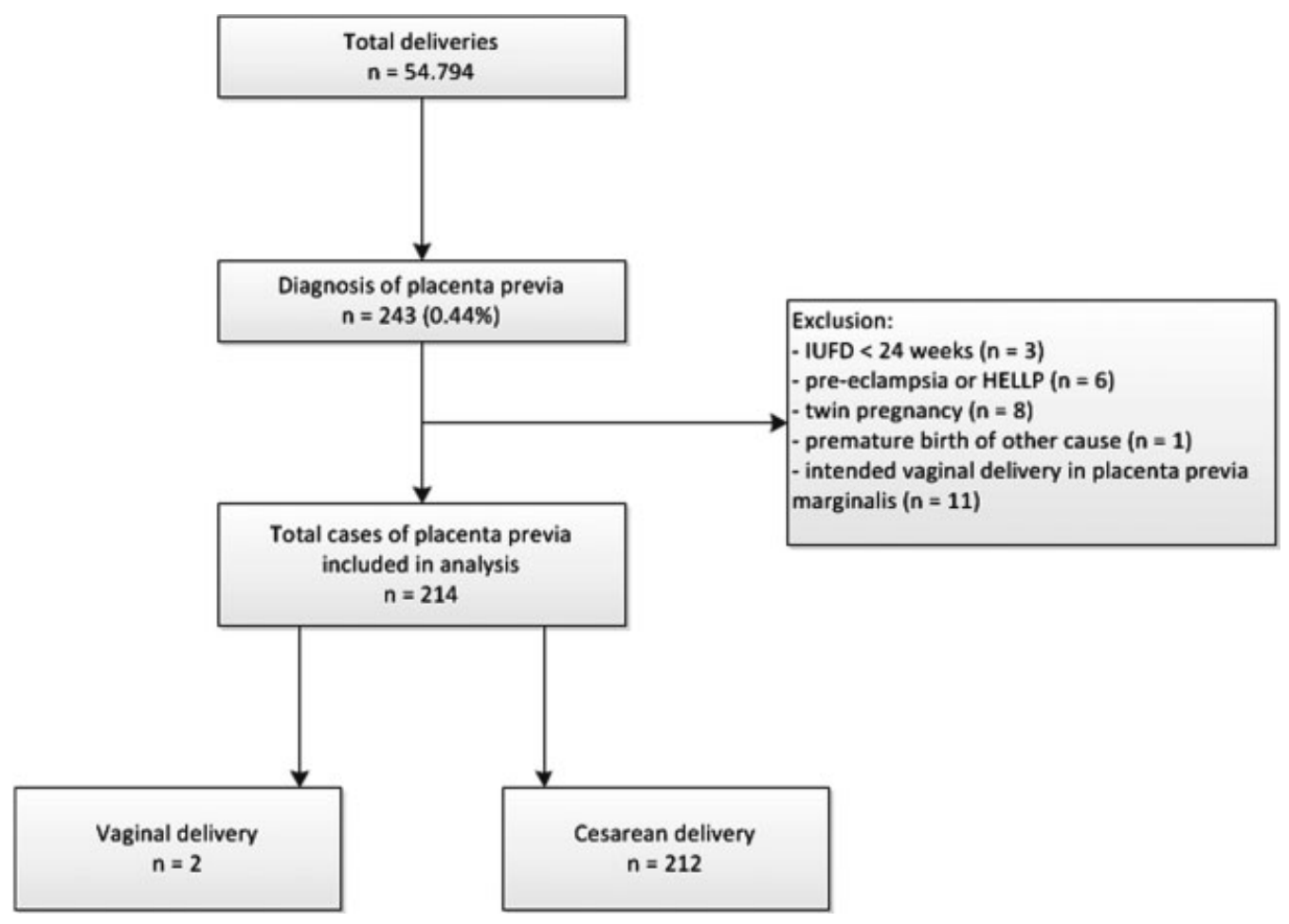

Fig. 1 Flowchart inclusion and exclusion criteria.

\section{Results}

A total of 54,794 women delivered in three hospitals in the study period, and 243 (0.44\%) women were diagnosed with placenta previa. We excluded 29 women: 8 women had a twin pregnancy, 6 had preeclampsia/HELLP, 3 had immature intrauterine fetal demise, 1 had multiorgan failure leading to premature delivery, and 11 had no scheduled cesarean delivery because of placenta previa marginalis with intended vaginal delivery (-Fig. 1).

Of 214 women included, 99\% (212/214) underwent cesarean delivery. The gestational age at delivery for both women with a delivery on the scheduled date and emergency delivery is shown in - Fig. 2. The mean gestational age at scheduled cesarean delivery was 38 weeks and 5 days, 57\% (121/214) of the women reached this scheduled date. The remaining $43 \%$ (93/214) delivered before the scheduled date of cesarean at a mean gestational age of 35 weeks and 3 days. Of these emergency deliveries, 46\% (43/93) was performed before 37 weeks of gestation and 22\% (20/93) before 32 weeks of gestation. Only two women delivered between 32 and 34 weeks of gestation.

- Fig. 3 shows the indications for emergency delivery and gestational age at delivery, 55\% (51/93) was due to hemorrhage alone, 36\% (33/93) because of early onset of labor, and $10 \%$ (9/93) because of nonreassuring fetal status.

- Table 1 shows the baseline characteristics and the results of the univariable and multivariable analyses. In the univariable analysis, variables associated with emergency delivery were history of cesarean section, history of premature delivery, maternal age, parity, type of placenta previa, presence of antepartum bleeding, hospital admission because of bleed- ing, antepartum use of ferrofumarate, and blood transfusion to compensate bleeding.

Based on the multivariable analysis, independent predictors for emergency delivery were history of cesarean section

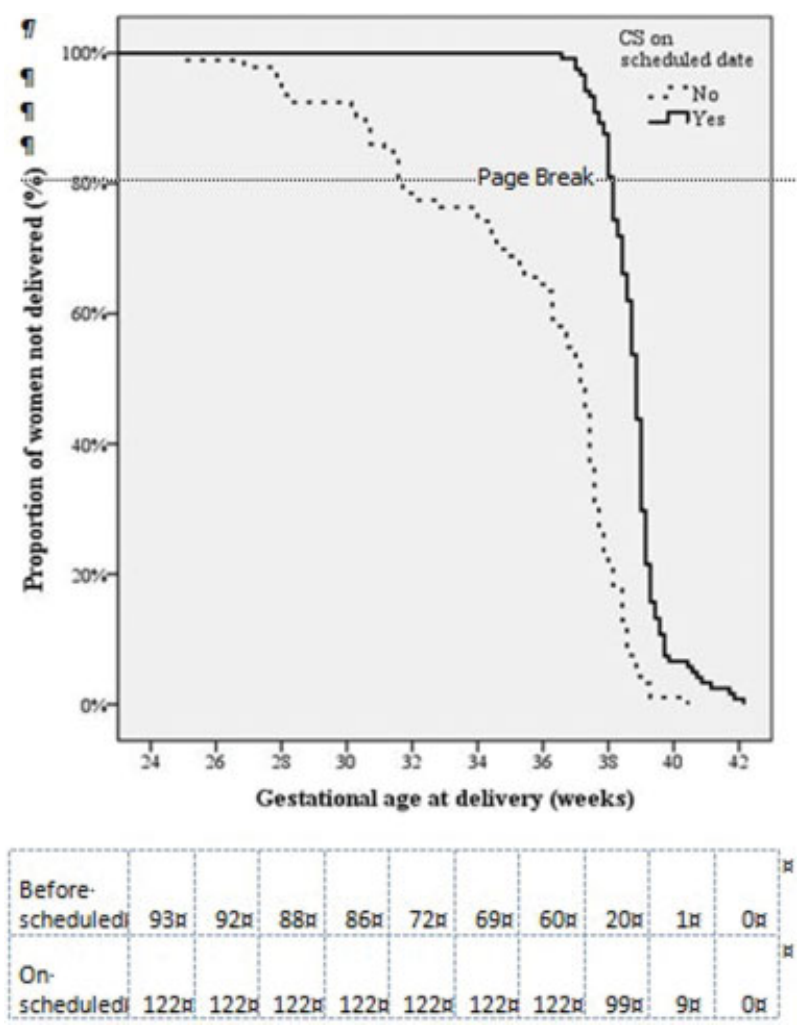

Fig. 2 Survival curve of scheduled versus emergency delivery. 


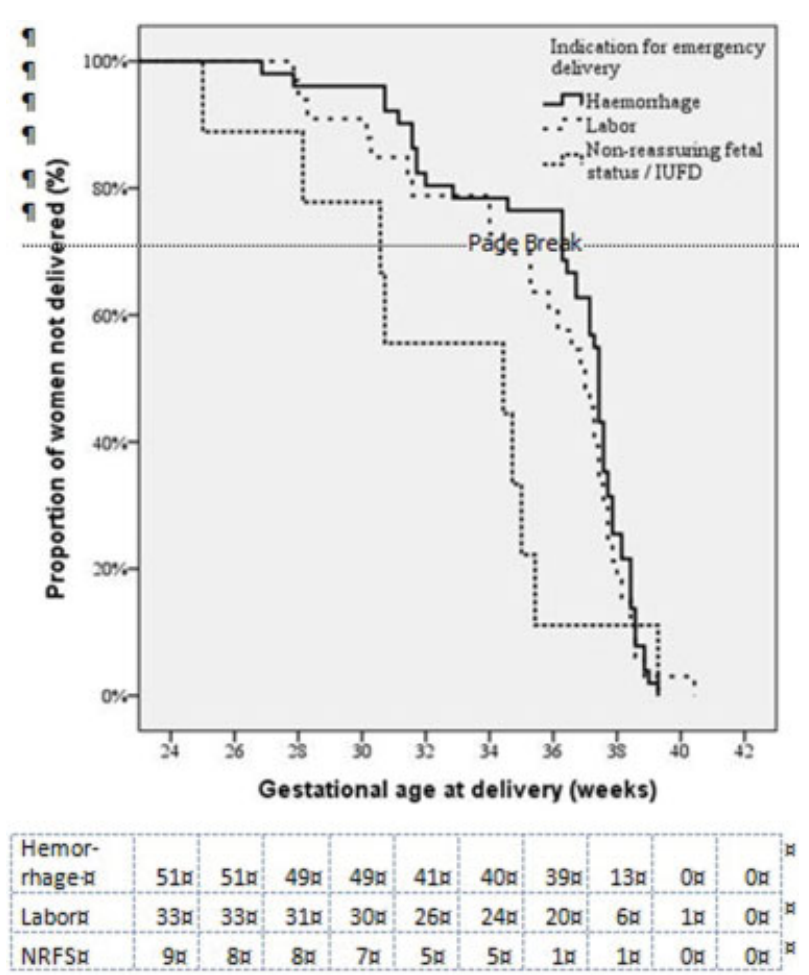

Fig. 3 Survival curve for indications for emergency delivery.

(OR, 4.7; 95\% CI, 1.2-12), presence of antepartum bleeding with one episode (OR, 7.5; 95\% CI, 2.5-23), two episodes (OR, 14; $95 \% \mathrm{CI}, 4.3-47$ ), three or more episodes (OR, 27; $95 \% \mathrm{CI}$, 8.3-90), and antepartum blood transfusion to compensate bleeding (OR, 6.4; 95\% CI, 1.7-23). Consequently, these variables were used in the final model for the prediction of emergency delivery. Comparison of the predictive factors regarding emergency delivery between women with placenta previa who delivered early preterm and late preterm showed no significant differences as shown in - Table 2.

The area under the ROC curve of the model was 0.83 (95\% $\mathrm{CI}, 0.78-0.89$ ). The model showed good agreement between predicted and observed probabilities (-Fig. 4). When divided in five separate risk categories, women in the lowest risk category (i.e., those without an episode of bleeding) almost never needed an emergency delivery, whereas women in the highest risk group virtually all underwent an emergency delivery, as shown in - Table 3. After internal validation by bootstrapping, the optimism corrected AUC was 0.821 .

\section{Comments}

\section{Main Findings}

In this study, we investigated predictors for emergency delivery in women with placenta previa. The incidence of placenta previa was $0.44 \%$. In $43 \%$ of the women, the delivery was emergent, at a mean gestational age of 35 weeks and 3 days. In multivariable regression, we identified a history of cesarean section, number of episodes of antepartum bleeding, and need for blood transfusion as independent predictors for an emergency delivery. A prediction model including these predictors showed good calibration and discrimination.

\section{Strengths and Limitations}

Our study is a multicenter cohort study reducing selection bias. Another strength of our study is the definition of antepartum bleeding to forestall variations in management; several different variables (hemorrhage leading to admission, the duration of admission, number of episodes of antepartum bleeding, and interventions needed to compensate) were extracted from the medical charts to objectify the amount of antepartum bleeding.

The timing of elective cesarean delivery as well as the decision to perform an emergency cesarean delivery are interventions of which the final decision is made by attending physicians. Because of the retrospective character and the absence of a prospective protocol, our study could not completely control for the varying management in women with symptomatic placenta previa. Although we tried to forestall this as much as possible by performing a multicenter study, the variability and the different strategies are present and a limitation in our study.

Furthermore, we used the results of the most recent ultrasound to confirm the diagnosis of placenta previa, since a second trimester placenta previa resolves in approximately $90 \%$ during pregnancy. ${ }^{12}$ This comes with a limited predictive value. On the contrary, the 32 weeks scan-for evaluation of placental localization in women with placenta previa-as confirmation of the diagnosis will not be available for all women, since around $9 \%$ of them already delivered by that time. Regarding our model for the prediction of emergency delivery in women with placenta previa, internal validation was assessed by bootstrapping and the model retained discriminatory capacity and goodness of fit in the validation samples. However, we do not possess of an external dataset for external validation.

\section{Interpretation}

The incidence of placenta previa found in our study is similar to the incidences reported in previous studies. ${ }^{2,13}$ From previous studies, it is already known that antepartum bleeding is a strong predictor for emergency delivery in women with placenta previa. However, in these retrospective cohort studies by Fishman et $\mathrm{al}^{5}$ and Lam et $a{ }^{6}{ }^{6}$ criteria for antepartum bleeding were not or insufficiently defined, such as currently in our study. A recent study by Luangruangrong et $\mathrm{al}^{14}$ also found an increased risk of preterm delivery in women with antepartum bleeding.

We found a history of cesarean section as predictor for emergency delivery. A previous cesarean section is a wellknown risk factor for placenta previa, but to our knowledge, it has not been described as a predictor for emergency delivery before, and future studies are needed to confirm this finding. We hypothesize that a placenta overlying a cesarean scar might be prone to antepartum bleeding because of a different placental adhesion to scar tissue than to normally developed endometrium. Potentially, the accrete placenta is a risk factor for antepartum bleeding rather than the history of cesarean 
Table 1 Baseline characteristics and results of univariable and multivariable analyses

\begin{tabular}{|c|c|c|c|c|c|c|}
\hline \multirow[t]{3}{*}{ Total } & \multicolumn{2}{|l|}{ Delivery } & \multicolumn{4}{|c|}{ Results of analysis } \\
\hline & \multirow{2}{*}{$\begin{array}{l}\text { On scheduled date } \\
n=121(56.5 \%)\end{array}$} & \multirow{2}{*}{$\begin{array}{l}\text { Emergency } \\
n=93(43.5 \%)\end{array}$} & \multicolumn{2}{|l|}{ Univariable } & \multicolumn{2}{|l|}{ Multivariable } \\
\hline & & & OR (95\% Cl) & $p$-Value & OR $(95 \% \mathrm{Cl})$ & $p$-Value \\
\hline \multicolumn{7}{|l|}{ Demographic characteristics } \\
\hline Maternal age, mean (SD) & $33.8(4.5)$ & $32.6(5.3)$ & $1.1(0.99-1.1)$ & 0.07 & & \\
\hline Ethnicity, Caucasian (\%) & $83(70)$ & $68(74.7)$ & $1.3(0.7-2.3)$ & 0.48 & & \\
\hline Smoking, $n(\%)$ & $13(11.4)$ & $10(12.2)$ & $1.1(0.5-2.7)$ & 0.87 & & \\
\hline BMI, mean (SD) & $23.9(4.8)$ & $24.4(6.4)$ & $1.0(0.96-1.1)$ & 0.57 & & \\
\hline \multicolumn{7}{|l|}{ Pregnancy characteristics } \\
\hline Primigravida, $n(\%)$ & $66(54.5)$ & $61(65.6)$ & $1.6(0.9-2.8)$ & 0.1 & & NS \\
\hline $\begin{array}{l}\mathrm{Hb} \text { at beginning of } \\
\text { pregnancy, mean in } \\
\mathrm{mmol} / \mathrm{L}(\mathrm{SD})\end{array}$ & $7.7(0.6)$ & $7.6(0.8)$ & $1.2(0.9-1.8)$ & 0.27 & & \\
\hline $\begin{array}{l}\text { Gestational age at delivery, } \\
\text { in mean wk (IQR) }\end{array}$ & $38.6(38.1-39.1)$ & $35.4(34-37.6)$ & & & & \\
\hline \multicolumn{7}{|l|}{ Type of placenta previa } \\
\hline Totalis & $62(51.2)$ & $56(60.2)$ & $0.89(0.35-2.2)$ & 0.78 & & \\
\hline Partialis & $16(13.2)$ & $11(11.8)$ & $0.67(0.37-1.2)$ & 0.2 & & NS \\
\hline Marginalis & $43(35.5)$ & $26(28)$ & Reference & & & \\
\hline \multicolumn{7}{|l|}{ History of } \\
\hline Curettage & $29(24.0)$ & $28(30.4)$ & $1.4(0.76-2.6)$ & 0.29 & & \\
\hline Cesarean section & $13(10.7)$ & $27(29.0)$ & $3.4(1.64-7.1)$ & 0.001 & $4.6(1.8-11)$ & $<0.01$ \\
\hline Uterine surgery & $5(4.1)$ & $3(3.2)$ & $0.77(0.18-3.3)$ & 0.73 & & \\
\hline Fibroid tumors & $6(5.0)$ & $3(3.2)$ & $0.64(0.16-2.6)$ & 0.53 & & \\
\hline Premature delivery $<37$ wk & $6(5.0)$ & $14(15.1)$ & $3.4(1.3-9.2)$ & 0.016 & & NS \\
\hline \multicolumn{7}{|l|}{ Antepartum bleeding } \\
\hline $\begin{array}{l}<32 \text { wk gestational age vs. } \\
\text { no bleeding }\end{array}$ & $33(27.3)$ & $56(60.2)$ & $18(6.5-50)$ & $<0.01$ & & $\mathrm{a}$ \\
\hline $\begin{array}{l}>32 \text { wk gestational age vs. } \\
\text { no bleeding }\end{array}$ & $35(28.9)$ & $32(34.4)$ & $9.7(3.4-27)$ & $<0.01$ & & $\mathrm{a}$ \\
\hline \multicolumn{7}{|l|}{ Episodes of antepartum bleeding } \\
\hline Bleeding vs. no bleeding & $67(55.4)$ & $88(94.6)$ & $14(5.4-37)$ & $<0.00$ & & \\
\hline 1 vs. no bleeding & $38(31.4)$ & $27(29.3)$ & $7.7(2.7-22)$ & $<0.01$ & $7.5(2.5-23)$ & $<0.01$ \\
\hline 2 vs. no bleeding & $16(13.2)$ & $23(25.0)$ & $16(5.1-47)$ & $<0.01$ & $14(4.3-47)$ & $<0.01$ \\
\hline$>3$ vs. no bleeding & $13(10.7)$ & $37(40.2)$ & $31(10-94)$ & $<0.01$ & $27(8.3-90)$ & $<0.01$ \\
\hline \multicolumn{7}{|c|}{ Admission (d) because of bleeding } \\
\hline $\begin{array}{l}1-7 \mathrm{~d} \text { vs. no admission } \\
\text { because of bleeding }\end{array}$ & $43(35.5)$ & $26(28.3)$ & $6.5(2.3-18)$ & $<0.01$ & & $\mathrm{a}$ \\
\hline $\begin{array}{l}>7 \text { days vs. no admission } \\
\text { because of bleeding }\end{array}$ & $24(19.8)$ & $61(66.3)$ & $27(9.8-77)$ & $<0.01$ & & $\mathrm{a}$ \\
\hline \multicolumn{7}{|c|}{ Compensation of antepartum bleeding } \\
\hline Ferrofumarate & $37(30.6)$ & $47(51.1)$ & $2.4(1.4-4.2)$ & 0.003 & & NS \\
\hline Blood transfusion & $3(2.5)$ & $22(23.9)$ & $12(3.6-43)$ & $<0.00$ & $6.6(1.8-24)$ & $<0.01$ \\
\hline
\end{tabular}

Abbreviations: BMI, body mass index; $\mathrm{Cl}$, confidence interval; IQR, interquartile range; NS, not significant; OR, odds ratio; SD, standard deviation. ${ }^{a}$ Not included in the multivariable analysis because of correlation. 
Table 2 Results of analysis on early preterm and late preterm deliveries

\begin{tabular}{|c|c|c|c|c|}
\hline & $\begin{array}{l}\text { Early preterm delivery } \\
<34 \text { wk, } n(\%)\end{array}$ & $\begin{array}{l}\text { Late preterm delivery } \\
34-37 \mathrm{wk}, n(\%)\end{array}$ & \multirow[t]{2}{*}{ OR (95\% Cl) } & \multirow[t]{2}{*}{$p$-Value } \\
\hline Total & $n=22(51 \%)$ & $n=21(49 \%)$ & & \\
\hline \multicolumn{5}{|l|}{ Demographic characteristics } \\
\hline Age mother, mean (SD) & $33.2(6.45)$ & $31.5(4.23)$ & $0.94(0.84-1.05)$ & 0.29 \\
\hline \multicolumn{5}{|l|}{ Pregnancy characteristics } \\
\hline Primigravida & $10(45.5)$ & $5(23.8)$ & $0.38(0.10-1.4)$ & 0.14 \\
\hline \multicolumn{5}{|l|}{ History of } \\
\hline Cesarean section & $7(31.8)$ & $5(23.8)$ & $1.5(0.39-5.7)$ & 0.56 \\
\hline Premature delivery & $6(27.3)$ & $3(14.3)$ & $2.3(0.48-11)$ & 0.3 \\
\hline \multicolumn{5}{|l|}{ Antepartum bleeding } \\
\hline$<32$ wk gestational age vs. no bleeding & $22(100)$ & $13(61.9)$ & & \\
\hline$>32$ wk gestational age vs. no bleeding & 0 & $8(38.1)$ & & \\
\hline \multicolumn{5}{|l|}{ Episodes of antepartum bleeding } \\
\hline Bleeding vs. no bleeding & 0 & $1(4.8)$ & & \\
\hline 1 vs. no bleeding & $10(45.5)$ & $8(38.1)$ & \multicolumn{2}{|l|}{ Reference } \\
\hline 2 vs. no bleeding & $6(27.3)$ & $5(23.8)$ & $1.04(0.23-4.7)$ & 0.96 \\
\hline$>3$ vs. no bleeding & $6(27.3)$ & $7(33.0)$ & $1.5(0.35-6.1)$ & 0.61 \\
\hline \multicolumn{5}{|l|}{ Admission ( $d$ ) because of bleeding } \\
\hline $1-7$ vs. $>7 d$ & $7(31.8)$ & $5(23.8)$ & $0.71(0.19-2.8)$ & 0.63 \\
\hline \multicolumn{5}{|l|}{ Compensation of antepartum bleeding } \\
\hline Ferrofumarate & $7(31.8)$ & $13(61.9)$ & $3.5(0.99-12)$ & 0.052 \\
\hline Blood transfusion & $8(36.4)$ & $8(38.1)$ & $1.08(0.31-3.7)$ & 0.91 \\
\hline \multicolumn{5}{|l|}{ Type of placenta previa } \\
\hline Totalis & $11(50)$ & $15(71.4)$ & $3,07(0.75-13)$ & 0.12 \\
\hline Partialis & $2(9.1)$ & $2(9.5)$ & $2.3(0.23-22)$ & 0.49 \\
\hline Marginalis & $9(40.9)$ & $4(19)$ & \multicolumn{2}{|l|}{ Reference } \\
\hline
\end{tabular}

Abbreviations: $\mathrm{Cl}$, confidence interval; OR, odds ratio.

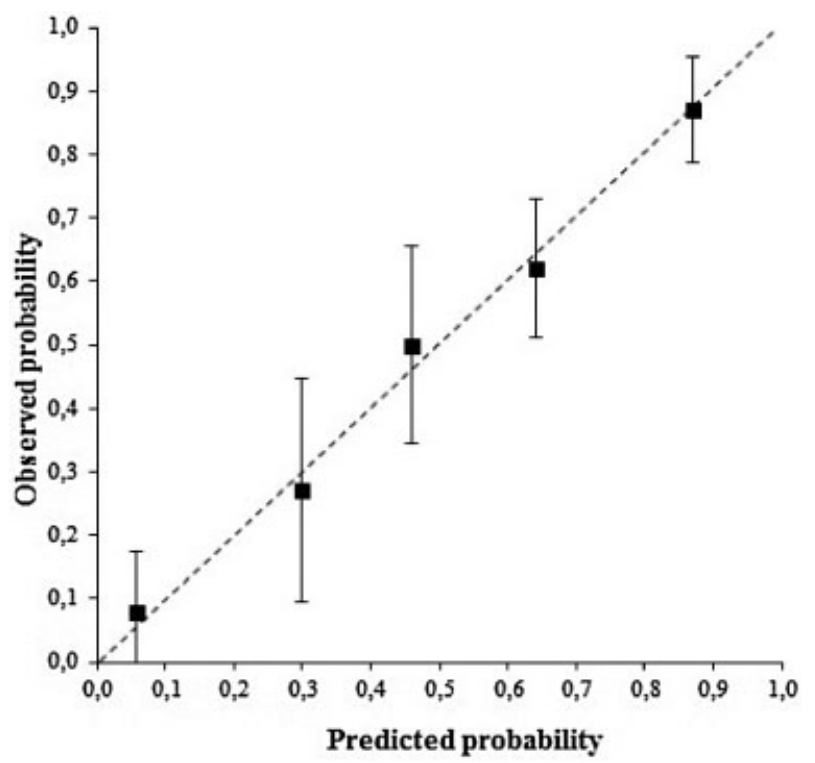

Fig. 4 Calibration plot. section itself. Although accrete placenta was equally distributed in our study cohort, the total count of this complication was low and our study is underpowered to analyze this hypothesis.

We found no difference in the frequency of emergency delivery in complete and incomplete placentae previa as was also concluded by Tuzovic ${ }^{13}$ but is in contrast with the results of Dola et al. ${ }^{15}$ Differences in these conclusions may be explained by differences in used diagnostic techniques, a broad variation in study periods and clinical management.

Cervical shortening as a predictive factor for preterm delivery in women with symptomatic placenta previa and antepartum bleeding has been reported. ${ }^{5,16}$ It seems plausible that a shortening cervix increases the risk of preterm delivery, but we could not take this variable into account since cervical length was not routinely measured in the Netherlands during the study period.

The 2011 NIHCD consensus conference publication on late preterm and early preterm deliveries advises to conduct the delivery between 36 and 37 weeks of gestation in women with 
Table 3 Frequency of predictors by risk category

\begin{tabular}{|l|l|l|l|l|l|l|}
\hline Risk category $^{\mathbf{a}}$ & $N$ & Previous cesarean section (\%) & Need for blood transfusion (\%) & \multicolumn{3}{|c|}{ Episodes of bleeding (\%) } \\
\cline { 4 - 8 } & & & & 1 & 2 & 3 \\
\hline 1 & 49 & 0 & 0 & 0 & 0 & 0 \\
\hline 2 & 59 & $12(20)$ & 0 & $49(83)$ & 0 & 0 \\
\hline 3 & 26 & 0 & 0 & 0 & $26(100)$ & 0 \\
\hline 4 & 39 & $9(23)$ & 0 & $9(23)$ & 0 & $30(77)$ \\
\hline 5 & 39 & $21(54)$ & $25(64)$ & $7(18)$ & $12(31)$ & $20(51)$ \\
\hline
\end{tabular}

aRisk for emergency delivery per category, respectively: $8,27,50,62$, and $87 \%$.

placenta previa. Our cohort consists of data before this publication with cesarean deliveries mainly scheduled after 38 weeks of gestation. A recent study by Balayla et $\mathrm{al}^{17}$ showed early-term delivery in placenta previa to be associated with fewer complications and no greater risk than late preterm delivery. Considering our results, of all women who were scheduled for cesarean delivery after 37 weeks of gestation, $63 \%$ reached this date. This suggests that with adequate selection, iatrogenic premature delivery may potentially be reduced. For example, the majority of women in our study who had emergency delivery before 37 weeks of gestation had antenatal bleeding in the second trimester. Potentially, women can be treated conservatively in an outpatient setting in the absence of bleeding before 32 weeks of gestation.

Finally, because three or more episodes of antenatal bleeding indicate a very high risk (87\%) of emergency delivery, scheduling delivery before 37 weeks of gestation with fetal lung maturation could be considered in these women to decrease neonatal respiratory distress syndrome. ${ }^{18}$ Since the effect of antenatal corticosteroids decreases after 7 days of administration ${ }^{19}$ and repeat doses of antenatal corticosteroids are associated with increased rates of behavioral disorders, timing is very important and we should restraint from routine administration of corticosteroids at every episode of antepartum bleeding. ${ }^{20,21}$

\section{Conclusion}

Our study results should be evaluated for application in individualized antenatal care concerning timing of delivery and administration of corticosteroids. This can potentially lead to conservative treatment in an outpatient setting in women at low risk for emergency delivery for the reason of beneficial neonatal outcome by reducing iatrogenic preterm delivery.

Note

This study was presented at the 35th Annual Meeting, The Pregnancy Meeting, Hilton San Diego Bayfront, San Diego, CA, February 2-7, 2015.

Conflict of Interest

None.

\section{References}

1 Johnston TA, Paterson-Brown S. Placenta Praevia, Placenta Praevia Accreta and Vasa Praevia: Diagnosis and Management. Royal College of Obstetricians and Gynaecologists. Available at: https://www.rcog.org.uk/globalassets/documents/guidelines/ gtg_27.pdf.Accessed2011

2 Ananth CV, Smulian JC, Vintzileos AM. The effect of placenta previa on neonatal mortality: a population-based study in the United States, 1989 through 1997. Am J Obstet Gynecol 2003;188(5):1299-1304

3 Zlatnik MG, Cheng YW, Norton ME, Thiet MP, Caughey AB. Placenta previa and the risk of preterm delivery. J Matern Fetal Neonatal Med 2007;20(10):719-723

4 Crane JM, Van den Hof MC, Dodds L, Armson BA, Liston R. Maternal complications with placenta previa. Am J Perinatol 2000;17(2): 101-105

5 Fishman SG, Chasen ST, Maheshwari B. Risk factors for preterm delivery with placenta previa. J Perinat Med 2012;40(1):39-42

6 Lam CM, Wong SF, Chow KM, Ho LC. Women with placenta praevia and antepartum haemorrhage have a worse outcome than those who do not bleed before delivery. J Obstet Gynaecol 2000;20(1): 27-31

7 Onwere C, Gurol-Urganci I, Cromwell DA, Mahmood TA, Templeton A, van der Meulen JH. Maternal morbidity associated with placenta praevia among women who had elective caesarean section. Eur J Obstet Gynecol Reprod Biol 2011;159(1):62-66

8 Crane JM, van den Hof MC, Dodds L, Armson BA, Liston R. Neonatal outcomes with placenta previa. Obstet Gynecol 1999;93(4): 541-544

9 Nørgaard LN, Pinborg A, Lidegaard Ø, Bergholt T. A Danish national cohort study on neonatal outcome in singleton pregnancies with placenta previa. Acta Obstet Gynecol Scand 2012;91(5):546-551

10 (NVOG) DAoOaG. Guideline Blood Loss in the Second Half of Pregnancy. Utrecht: The Dutch Society of Obstetrics and Gynecology; 2011

11 Smith GC, Seaman SR, Wood AM, Royston P, White IR. Correcting for optimistic prediction in small data sets. Am J Epidemiol 2014; 180(3):318-324

12 Neilson JP. Interventions for suspected placenta praevia. Cochrane Database Syst Rev 2003;(2):CD001998

13 Tuzovic L. Complete versus incomplete placenta previa and obstetric outcome. Int J Gynaecol Obstet 2006;93(2):110-117

14 Luangruangrong P, Sudjai D, Wiriyasirivaj B, Paloprakarn C. Pregnancy outcomes of placenta previa with or without antepartum hemorrhage. J Med Assoc Thai 2013;96(11):1401-1407

15 Dola CP, Garite TJ, Dowling DD, Friend D, Ahdoot D, Asrat T. Placenta previa: does its type affect pregnancy outcome? Am J Perinatol 2003;20(7):353-360

16 Ghi T, Youssef A. Ultrasonographic cervical length and risk of hemorrhage in pregnancies with placenta previa. Obstet Gynecol 2010;116(6):1458-1459, author reply 1458-1459

17 Balayla J, Wo BL, Bédard MJ. A late-preterm, early-term stratified analysis of neonatal outcomes by gestational age in placenta 
1414 Emergency Delivery in Placenta Previa Ruiter et al.

previa: defining the optimal timing for delivery. J Matern Fetal Neonatal Med 2015;28(15):1756-1761

18 Roberts D, Dalziel S. Antenatal corticosteroids for accelerating fetal lung maturation for women at risk of preterm birth. Cochrane Database Syst Rev 2006;(3):CD004454

19 Melamed N, Shah J, Soraisham A, et al. Association between antenatal corticosteroid administration-to-birth interval and outcomes of preterm neonates. Obstet Gynecol 2015;125(6):1377-1384
20 French NP, Hagan R, Evans SF, Mullan A, Newnham JP. Repeated antenatal corticosteroids: effects on cerebral palsy and childhood behavior. Am J Obstet Gynecol 2004;190(3): 588-595

21 Stutchfield PR, Whitaker R, Gliddon AE, Hobson L, Kotecha S, Doull IJ. Behavioural, educational and respiratory outcomes of antenatal betamethasone for term caesarean section (ASTECS trial). Arch Dis Child Fetal Neonatal Ed 2013;98(3):F195-F200 